\title{
Host specialization of parasitoids and their hyperparasitoids on a pair of syntopic aphid species
}

\section{Journal Article}

Author(s):

Schär, Sämi; Vorburger, Christoph

Publication date:

2013-10

Permanent link:

https://doi.org/10.3929/ethz-b-000071788

Rights / license:

In Copyright - Non-Commercial Use Permitted

Originally published in:

Bulletin of Entomological Research 103(5), https://doi.org/10.1017/S0007485313000114 


\title{
Host specialization of parasitoids and their hyperparasitoids on a pair of syntopic aphid species
}

\author{
Sämi Schär ${ }^{1 *}+$ and Christoph Vorburger ${ }^{2,3}$ \\ ${ }^{1}$ Institute of Evolutionary Biology and Environmental Studies, University of \\ Zurich, Winterthurerstrasse 190, 8057 Zürich, Switzerland: ${ }^{2}$ Institute of \\ Integrative Biology, ETH Zürich, Switzerland: ${ }^{3}$ EAWAG, Swiss Federal \\ Institute of Aquatic Science and Technology, Überlandstrasse 133, \\ 8600 Dübendorf, Switzerland
}

\begin{abstract}
Parasitoids of herbivorous insects have frequently evolved specialized lineages exploiting hosts occurring on different plants. This study investigated whether host specialization is also observed when closely related parasitoids exploit herbivorous hosts sharing the same host plant. The question was addressed in economically relevant aphid parasitoids of the Lysiphlebus fabarum group. They exploit two aphid species (Aphis fabae cirsiiacanthoides and Brachycaudus cardui), co-occurring in mixed colonies (syntopy) on the spear thistle (Cirsium vulgare). Two morphologically distinguishable parasitoid lineages of the genus Lysiphlebus were observed and each showed virtually perfect host specialization on one of the two aphid species in this system. From A. f. cirsiiacanthoides, only females emerged that morphologically belonged to Lysiphlebus cardui, while males and females belonging to L. fabarum hatched from B. cardui. Microsatellite analyses indicated clear genetic differentiation of L. fabarum and L. cardui. L. cardui comprised only two distinct asexual lineages, one of which predominated throughout the area investigated. Population genetic analysis of sexual L. fabarum showed evidence for relatively strong spatial structuring and limited dispersal ability. Hyperparasitoids emerged from a large proportion of aphid mummies. One species, Pachyneuron aphidis, was significantly associated with B. cardui/L. fabarum mummies, indicating that host specialization may even extend to the trophic level above parasitoids.
\end{abstract}

Keywords: host specialization, host associated genetic differentiation, HAD, local adaptation, hyperparasitism, dispersal, Lysiphlebus, Aphis, Brachycaudus, Cirsium

(Accepted 17 January 2013; First published online 13 March 2013)

\section{Introduction}

The diversity of life keeps fascinating biologists and requires explanation. Diversity is not distributed equally

*Author for correspondence

Phone: +45 353-21238

Fax: +45 353-21250

E-mail: SSchar@bio.ku.dk, saemi.schaer@gmail.com

+Present address: Centre for Social Evolution, Department of Biology, University of Copenhagen, Universitetsparken 15, 2100 Copenhagen $\varnothing$, Denmark. within the tree of life. Some clades comprise many more species than others. Insects show an extremely high number of species compared to other classes of organisms (Stork, 1988; Labandeira \& Sepkoski, 1993; Mayhew, 2007), and phytophagous insects are particularly diverse (Mitter et al., 1988). This is often explained in terms of their intimate association and strong dependency on their host plants, promoting specific adaptations which in turn may result in genetically based trade-offs in performance on different hosts and ultimately in ecological speciation (Smith, 1966; Jaenike 1990; Berlocher \& Feder, 2002; Nosil 2007). Other groups with unusual species richness are the parasitic wasps from the superfamilies Ichneumonoidea and Chalcidoidea. They 
comprise at least 45,000 described species (Gaston, 1991), but other estimates go up to one million (Godfray, 1994; Quicke, 1997). This tremendous diversity, just as in phytophagous insects, could be because of ecological speciation (Funk, 1998; Schluter, 2001; Stireman et al., 2006). Like their herbivorous host insects, parasitoids are often characterized by narrow specialization and/or host-associated genetic differentiation within species using multiple hosts (Pashley, 1986; Stireman et al., 2005). Such host races may arise sympatrically and eventually evolve into different species as disruptive selection continues and barriers to gene flow emerge (Bush, 1969; Craig et al., 1997; Drès \& Mallet, 2002). This raises the intriguing possibility that diversification of plant feeding insects can also lead to diversification of their parasitoids, a phenomenon that has been described as cascading host-associated genetic differentiation or sequential sympatric speciation (Stireman et al., 2006; Forbes et al., 2009; Feder \& Forbes, 2010).

The genus Lysiphlebus (Hymenoptera: Braconidae) consists of several species of small aphid parasitoids. They use a variety of aphid hosts (Starý, 2006). Most common in Europe are species of the Lysiphlebus fabarum group, which is characterized by the frequent occurrence of all-female populations reproducing by thelytokous parthenogenesis (Belshaw et al., 1999; Starý, 1999; Sandrock \& Vorburger, 2011). The group comprises L. fabarum (Marshall), Lysiphlebus cardui (Marshall) and Lysiphlebus confusus (Tremblay \& Eady), which are morphologically very similar. L. confusus is distinguished from the other two species by a fringe of long setae on the margin of the forewing, and L. cardui is distinguished from L. fabarum by relatively long and erect setae on the hind femora (Starý, 1966). However, a study by Belshaw et al. (1999) and more recent work employing mitochondrial DNA sequences as well as nuclear microsatellite markers casts doubt on the validity of this distinction, because morphology does not reliably predict genetic relationships in the $L$. fabarum group. All three morphotypes are polyphyletic (Sandrock et al., 2011a; Schär, Rouchet \& Vorburger, unpublished data). Nevertheless, for simplicity and for the lack of alternative descriptions, the species names will be maintained in this article.

Parasitoids of the L. fabarum group occur on a wide range of aphid-plant communities and exhibit a substantial degree of host-associated differentiation (HAD) at presumably neutral molecular markers (Belshaw et al., 1999; Sandrock et al., 2007, 2011a), indicating host specialization and limited gene flow between wasps exploiting different aphids. However, specialization may be facilitated by the fact that different aphid species typically feed on different plant species, generating local geographic separation of their parasitoid populations (e.g., Kavallieratos et al., 2008; Tomanović et al., 2009). An exception is Lysiphlebus on the thistle Cirsium vulgare (Savi) (Asteraceae) on which they attack two aphid species, Brachycaudus cardui (Linné) (Hemiptera: Aphididae) and Aphis fabae cirsiiacanthoides (Scolpoli) (Hemiptera: Aphididae). These aphids can be considered as syntopic because they often feed in mixed colonies on stems and leaves of the same individual plants and during the same time of the year (e.g., Klinkhamer \& De Jong, 1993; Blackman \& Eastop, 2000; see the Results section). Observations by Starý (2006) suggest that B. cardui is parasitized by arrhenotokous (sexual) Lysiphlebus and A. f. cirsiiacanthoides is usually parasitized by thelytokous wasps and that the wasps attacking these two hosts also show some morphological differentiation. In consequence, Starý (2006) proposed raising L. fabarum-like parasitoids attacking $B$. cardui to the level of a separate, host-specific taxon
(=Lysiphlebus brachycaudi Starý), but this species has not yet been formally described. Cuticular hydrocarbon profiles (Liepert, 1996) and nuclear genomic DNA confirm their separate status within the L. fabarum group, but mitochondrial DNA sequence divergence does not clearly support the distinction of 'L. brachycaudi' as a separate species (Belshaw et al., 1999, Sandrock et al., 2011a). Here, we address this issue with a systematic field study on the host use and the genetic population structure of Lysiphlebus parasitoids attacking aphids on the host plant $C$. vulgare. We also aim to shed some light on the poorly known patterns of gene flow and dispersal in this group on the scale of landscape-metapopulations. In addition, we investigated host use at the next trophic level. Parasitoids feeding on phytophagous insect, here aphids, are so-called primary parasitoids. Primary parasitoids may themselves be consumed by hyperparasitoids. The parasitoid community of aphids feeding on C. vulgare gets exploited by a number of such hyperparasitoids. Host associations of hyperparasitoids under syntopic conditions are poorly known. To document and compare those was therefore another objective of our research.

\section{Methods}

Sampling

Samples were collected from 22 sites in northern Switzerland (fig. 1a), either in May/June 2007 or between June and August 2009. Sites consisted of patches of C. vulgare harbouring colonies of one or both focal aphid species, and they were separated by 0.5 and $101 \mathrm{~km}$ (fig. 1a). Plant parts containing aphid mummies were cut and sealed in cellophane bags. A total of 977 aphid mummies were collected: 460 A. f. cirsiiacanthoides mummies and 517 B. cardui mummies.

\section{Parasitoid eclosion and classification}

After collection the still uneclosed mummies were carefully removed from the plants and placed individually in gelatin capsules. This treatment allowed unambiguous identification of the host aphid of each individual wasp. After the parasitoids had eclosed from mummies they were killed with vaporized ethyl acetate and then classified by use of the available taxonomic literature (Genera Lysiphlebus and Binodoxys: Starý (1966), genera Asaphes and Pachyneuron: de Vere Graham (1969), genus Syrphophagus: Erdös (1964), genus Dendrocerus: Fergusson (1980), genus Alloxysta: Andrews (1978)). The final set of ecological data contained information on the date of collection, the site of collection, the individual host plant, the host aphid species as well as the species and sex of each eclosed parasitoid wasp. Aphid parasitoids of the genus Lysiphlebus all belonged to the L. fabarum group and were further distinguished based on the presence or absence of long semi-erect setae on the femora (absent $=L$. fabarum, present $=L$. cardui) and then stored in $96 \%$ ethanol at $-20^{\circ} \mathrm{C}$ until molecular investigation. We did not find any individuals belonging to L. confusus (females with a fringe of long setae along the margin of the forewing) in our samples.

\section{DNA extraction and microsatellite analysis}

The DNA was prepared using the Chelex ${ }^{\circledR}$ method: a single wasp was placed in a 1.5-ml Eppendorf tube and squashed in $100 \mu \mathrm{l}$ of a $5 \%$ Chelex solution (BioRad). After that, $5 \mu \mathrm{l}$ 


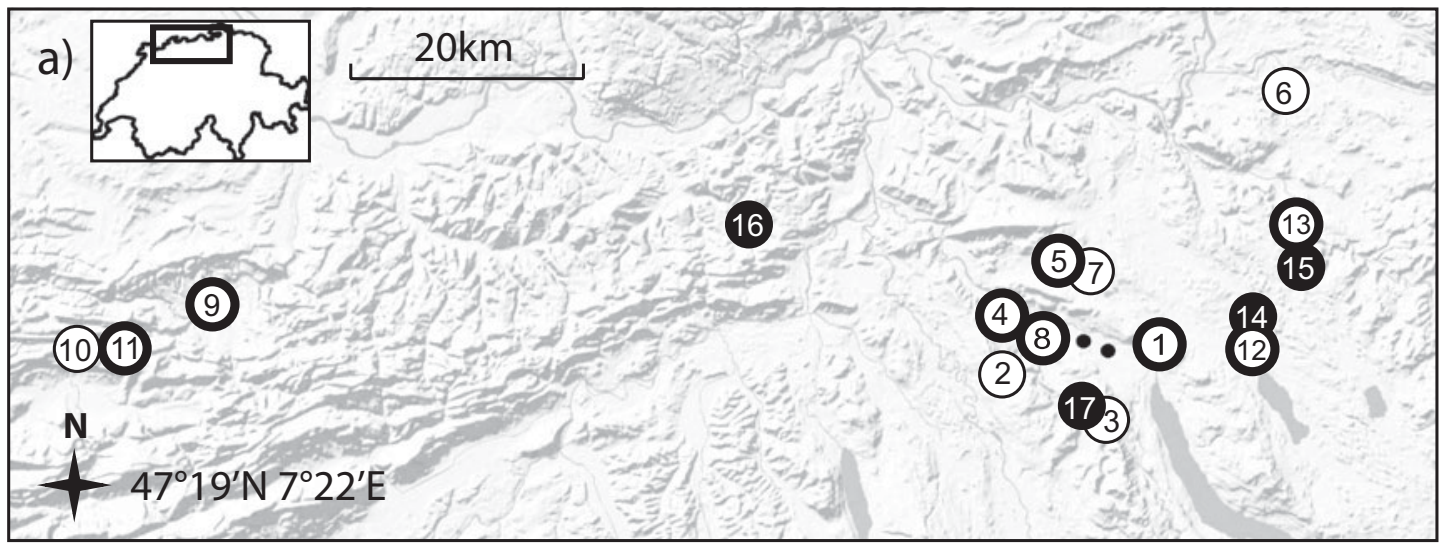

b)

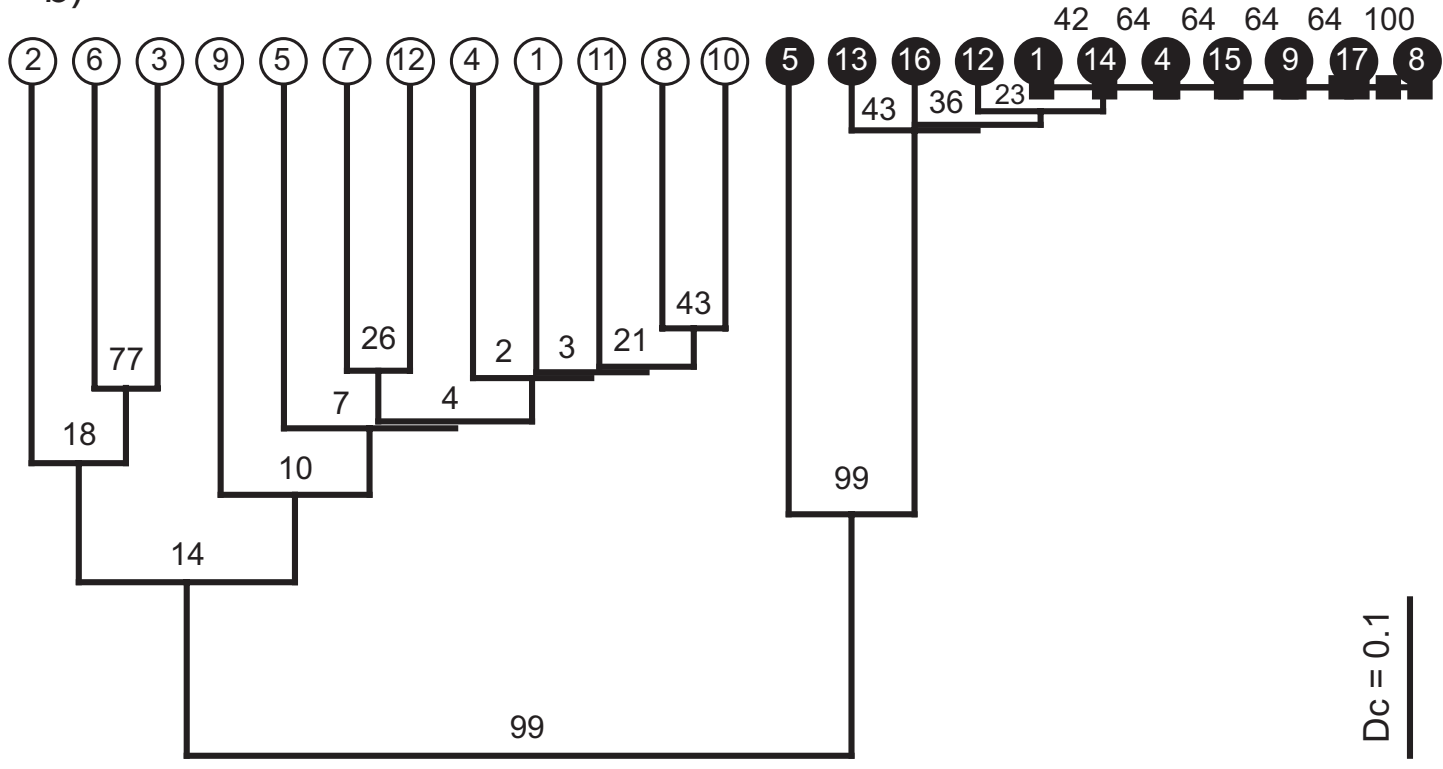

c)

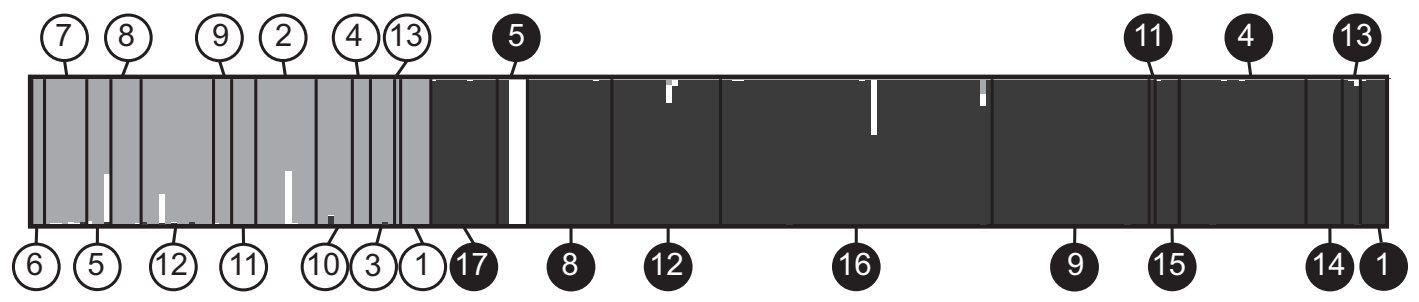

Fig. 1. Map (a) UPGMA tree (b) and individual cluster assignments (c) of Lysiphlebus using two different host aphids on C. vulgare in northern Switzerland. Lysiphlebus populations hatching from B. cardui mummies are shown as white circles, those hatching from A. f. cirsiiacanthoides mummies as black circles and mixed populations are indicated by white circles with bold black frames. The small black points mark sites where only hyperparasitoids were found. The tree in (b) is based on Cavalli-Sforza Chord distance (Dc), UPGMA algorithm and 5000 bootstraps on loci (values are rounded percentages) and includes haploid male and diploid female genotypes (scale bar: Cavalli-Sforza Chord=0.1). (c) Shows the STRUCTURE output with the most probable number of $K=3$ for the diploid Lysiphlebus females. Each vertical line shows one individual and black lines separate populations. The shaded segments of the lines represent the estimated probability of an individual being member of one of the three inferred clusters. The analyses in (b) and (c) are based on seven presumably neutral microsatellite markers.

Proteinase $K$ were added, and the mixture was incubated overnight at $56^{\circ} \mathrm{C}$. The next day, the content of the tubes was mixed again, heated at $95^{\circ} \mathrm{C}$ for $15 \mathrm{~min}$ and centrifuged at $7000 \mathrm{~g}$ for $5 \mathrm{~min}$. Finally, $50 \mu \mathrm{l}$ of the clear supernatant were separated in a fresh Eppendorf tube and used as DNA template in PCRs.

All wasps belonging to the L. fabarum group were genotyped at eight microsatellite markers developed for 
L. fabarum (Lysi03, Lysi05, Lysi06, Lysi07, Lysi08, Lysi13, Lysi15, and Lysi16; Sandrock et al., 2007) and one for Lysiphlebus testaceipes (L5a12; Fauvergue et al., 2005), following a published PCR protocol (Sandrock et al., 2007). The fragment analysis was carried out on an ABI 3730 automated sequencer, using an internal size standard (GeneScan 500 LIZ). Electropherograms were analyzed with the program GENEMAPPER version 3.7 (Applied Biosystems).

\section{Comparing host associations}

To test for biases in host use of the different parasitoids species, we used generalized linear-mixed models including all 977 collected aphid mummies. The analysis was carried out using PROC GLIMMIX (SAS 9.2; SAS Institute, Cary, NC, USA). Hatching events of each parasitoid species were coded as a binary response variable with hatching coded as 1 . The host aphid species was treated as a fixed effect and the site and the interaction between site and aphid species were included as random effects in the model to correct for variation in host use between sites, non-independence of replicates within sites and local host-abundance. We assumed a binary distribution of the response variable and chose the logit-link function. This type of analysis caused some problems when testing for host associations of aphid parasitoids because their perfect host specialization led to non-convergence of the models. In those cases, we introduced one artificial hatchingevent data point at a randomly chosen site of the parasitoid species using the non-associated aphid species. This allowed us to calculate the conservative upper limit of the $P$-value for host associations.

\section{Genetic data analysis}

Owing to the haplodiploid sex-determination system in the investigated Lysiphlebus parasitoids, only diploid female genotypes were considered in all analyses except for the population tree based on allele frequencies, which were estimated including the haploid male genotypes (fig. 1b).

Owing to the high fraction of thelytokous L. cardui samples, mostly belonging to the same clonal lineage, deviations from linkage and Hardy-Weinberg equilibria were only calculated for the subset of sexually reproducing $L$. fabarum. The analysis of linkage disequilibrium between pairs of loci was done using exact probability tests (Guo \& Thompson, 1992) with the program GENEPOP 4.1.0 (Raymond \& Rousset, 1995). For the diploid $L$. fabarum females, $F_{\mathrm{IS}}$ and global as well as pairwise $F_{\text {ST }}$ values (Weir \& Cockerham, 1984) were calculated using the software FSTAT (Goudet, 2005). Isolation by distance was assessed by testing for a correlation between genetic distance $\left(F_{\mathrm{ST}} /\left(1-F_{\mathrm{ST}}\right)\right)$ (Slatkin, 1995) and log-transformed straight line geographic distance as per Rousset (1997). The geographic distance between sample sites was measured using the software 'Geographic Distance Matrix Generator 1.2.3' (Ersts, 2007) from WSG84 coordinates. Matrix correlation was analyzed using a Mantel-test with 10,000 permutations in Arlequin v 3.1 (Excoffier et al., 2005).

Genetic diversity, frequencies of multilocus genotypes (MLGs) of Lysiphlebus as well as the probability of multiple copies of the same MLG being produced independently by sexual recombination $\left(P_{\text {sex }}\right)$ were analyzed by use of the program GenClone v 2.0 (Arnaud-Haond \& Belkhir, 2007) according to the 'round robin fashion' mode
(Parks \& Werth, 1993). A matrix of allelic distances was plotted for the MLGs of L. cardui to assess the allelic distances between them.

A microsatellite-based Unweighted Pair Group Method with Arithmetic Mean (UPGMA) tree of all Lysiphlebus populations defined as individuals from the same site and host aphid was created using the software packages Populations v 1.2.32 (Langella, 1999) and TreeView v 1.6.6 (Page, 1996) (fig. 1b). The tree was calculated based on the Cavalli-Sforza Chord distance method (Cavalli-Sforza \& Edwards, 1967) and using the UPGMA (Sneath \& Sokal, 1973). Haploid male genotypes were included for the calculation of genetic distances between populations based on allele frequencies within populations. A total of 5000 bootstraps on locus were performed to estimate the support of the nodes of the tree.

In addition, we investigated genetic structuring using Bayesian clustering as implemented in STRUCTURE v 2.3.3 (Pritchard et al., 2000; Falush et al., 2003). We chose the admixture model, which assumes that each individual potentially received a part of its genome from each of the $K$ ancestor populations and assumed correlated allele frequencies among populations. The following parameters were chosen: burnin length of 100,000 , followed by 1 million MCMC iterations. Ten independent runs for each value of $K$ were generated to test for consistency between runs. The values for $K$ varied between two and seven between independent runs of the program. The most accurate number of populations $(K)$ was visually examined when plotting $K$ against $\Delta K$ and using the Evanno method in STRUCTURE HARVESTER (Earl \& vonHolt, 2012). The program Distruct v 1.1 (Rosenberg, 2004) was used to visualize the results of the structure output (fig. 1c).

\section{Results \\ Wasp diversity}

A total of 589 parasitoid wasps hatched from the 977 aphid mummies collected. They were classified into five families, seven genera and at least nine different species (Lysiphlebus fabarum and L. cardui, Binodoxys angelicae (Haliday) (Hymenoptera: Braconidae), Alloxysta sp. (Foerster) (Hymenoptera: Figitidae), Asaphes vulgaris (Walker), Asaphes suspensus (Nees) and Pachyneuron aphidis (Bouché) (Hymenoptera: Pteromalidae), Dendrocerus carpenteri (Curtis) and D. laevis (Ratzeburg) (Hymenoptera: Megaspilidae) and Syrphophagus aphidivorus (Mayr) (Hymenoptera: Encyrtidae) (table 1). The species belonging to the genera Lysiphlebus and Binodoxys are aphid parasitoids, whereas the other genera are all hyperparasitoids (Müller et al., 1999). The taxonomically poorly resolved Alloxysta species were not classified to species level because comprehensive taxonomic literature is lacking for that genus in the palaearctic region (Andrews, 1978; Evenhuis \& Kiriak, 1985).

A total of 251 Lysiphlebus wasps (97.3\% of all primary parasitoids) hatched from mummies collected on 38 different plants in 17 different sampling localities. Both species were collected at eight sites, five sites yielded only L. fabarum and four sites only L. cardui (table 1, fig. 1a). In five cases, both parasitoid species occurred together on the same plant, on 14 plants only L. fabarum was found and on 19 plants only L. cardui. 
Table 1. Sample sizes and host use of all collected parasitoid species. Significant associations between parasitoids and aphids are indicated with bold letters and by asterisks (generalized linear mixed-model, ${ }^{*} P<0.05,{ }^{* *} P<0.01,{ }^{* * *} P<0.001$ ).

\begin{tabular}{|c|c|c|c|c|}
\hline \multirow[t]{2}{*}{ Parasitoid species } & \multirow[t]{2}{*}{$N$} & \multirow[t]{2}{*}{$N$ (sites) } & \multicolumn{2}{|c|}{ Host mummy species } \\
\hline & & & Aphis fabae cirsiiacanthoides & Brachycaudus cardui \\
\hline \multicolumn{5}{|l|}{ Aphid parasitoids: } \\
\hline Lysiphlebus cardui & 154 & 13 & $154^{* * *}$ & 0 \\
\hline Binodoxys angelicae & 7 & 1 & 7 & 0 \\
\hline \multicolumn{5}{|l|}{ Hyperparasitoids: } \\
\hline Asaphes vulgaris & 7 & 4 & 1 & 6 \\
\hline Dendrocerus carpenteri & 43 & 7 & 9 & 34 \\
\hline Dendrocerus laevis & 1 & 1 & 1 & 0 \\
\hline Pachyneuron aphidis & 112 & 13 & 23 & $89^{*}$ \\
\hline Syrphophagus aphidivorus & 120 & 16 & 59 & 61 \\
\hline
\end{tabular}

\section{Sex ratios}

All 154 individuals of L. cardui were females, consistent with thelytokous reproduction in this lineage. The sex ratio in L. fabarum was 31 male and 66 female individuals, that is approximately $1 / 3$ males. Similarly female-biased sex ratios were also observed in hyperparasitoids. The difference in sex ratio between $L$. cardui and $L$. fabarum was highly significant (Fisher's exact test, $P<0.001$ ).

\section{Host associations}

The host associations of the two aphid parasitoid taxa belonging to the genus Lysiphlebus were clearly distinct and non-overlapping. All wasps determined as L. cardui enclosed from mummies of $A$. $f$. cirsiiacanthoides, whereas all wasps determined as $L$. fabarum enclosed from mummies of $B$. cardui (host association of L. fabarum with B. cardui: $F_{1,14}=15.43$, $P<0.002$, L. cardui with $A$. f. cirsiiacanthoides: $F_{1,14}=22.06$, $P<0.001$, table 1). B. angelicae eclosed exclusively from A. f. cirsiiacanthoides mummies, but only seven individuals from a single site were found overall, precluding a firm statement on its host association. Hyperparasitoids showed less pronounced host associations and all species represented by more than one individual hatched from both aphid species. Nevertheless, the hyperparasitoid species $P$. aphidis emerged significantly more often from $B$. cardui/L. fabarum mummies than expected by chance $\left(F_{1,14}=6.20, P=0.026\right.$, table 1$)$. The overall relative proportion of hyperparasitoids was much higher in B. cardui mummies compared to A.f. cirsiiacanthoides mummies (Fisher's exact test, $P<0.001$, table 1), suggesting higher vulnerability to hyperparasitism of L. fabarum compared with $L$. cardui. We did not observe any phenological differences between $L$. fabarum and $L$. cardui which could bias our findings.

\section{Microsatellite variation}

Eight polymorphic microsatellite markers amplified consistently in all sampled populations. Marker Lysi16 amplified only in Lysiphlebus parasitoids hatching from A. f. cirsiiacanthoides mummies (L. cardui) but not in those hatching from B. cardui mummies (L. fabarum), providing a first indication of genetic differentiation between these two host-associated lineages. This locus was therefore excluded from all further analyses. The marker Lysi07 is not neutral because it is usually linked with the reproductive mode in the L. fabarum group (Sandrock \& Vorburger, 2011) and was excluded from all analyses of the genetic population structure. These were carried out with the seven remaining microsatellite loci.

No significant deviations from linkage equilibrium were found among the seven microsatellite markers in the sexual L. fabarum populations, consistent with two detailed reports (Sandrock et al., 2007, 2011a). The mean observed heterozygosity in $L$. fabarum $\left(H_{\mathrm{obs}}=0.204\right)$ was lower than expected heterozygosity $\left(H_{\exp }=0.234\right)$. In accordance with this homozygote excess, the mean $F_{\mathrm{IS}}$-value of $0.211 \pm 0.096$ (SE) was significantly larger than zero $(P<0.001)$. There was also significant genetic differentiation among populations of L. fabarum (global $F_{\mathrm{ST}}=0.296 \pm 0.064, P<0.001$ ), but the degree of pairwise differentiation between populations was unrelated to the geographic distance separating them, as we could not detect any isolation by distance across the study area $\left(r=-0.014, \quad R^{2}<0.001, \quad P=0.539\right)$. The high $F_{\mathrm{IS}}$ values combined with strong genetic differentiation unrelated to geographic distance suggests that there may be some family structure in our data (e.g., from collecting multiple offspring of the same female per site), which would not be surprising. Yet because we could only include data coming from just 66 sexual, diploid females spread across 13 collection sites, all population genetic indices should be interpreted cautiously.

Genetic diversity was extremely low in L. cardui. The 141 samples with completely analyzed genotypes comprised only seven distinct MLGs. One of those (MLG 3) was shared by $91 \%$ of the individuals (table 2). Another $7 \%$ consisted of very closely related genotypes, differing by one and four alleles only from the most abundant MLG 3 and by one and six alleles among each other (table 1). Interestingly, the L. cardui samples also comprised three individuals with an additional, very distinct MLG which differed by 10 and 13 alleles from all other L. cardui genotypes (MLG 7 in table 2). This genotype was just discovered in one sampling site, namely 'Buchs $\mathrm{ZH}^{\prime}$ (no. 5 in fig. 1), where it co-occurred with the most abundant MLG 3 (fig. 1c). The probability of being generated independently by sexual recombination $\left(P_{\text {sex }}\right)$ was below 0.001 for all MLGs of L. cardui represented by more than one individual. A very different pattern was observed in L. fabarum. Among the 57 females with completely analyzed genotypes, 43 distinct MLGs were found. These results are consistent with 
Table 2. Abundance and microsatellite genotypes of the seven observed L. cardui MLGs.

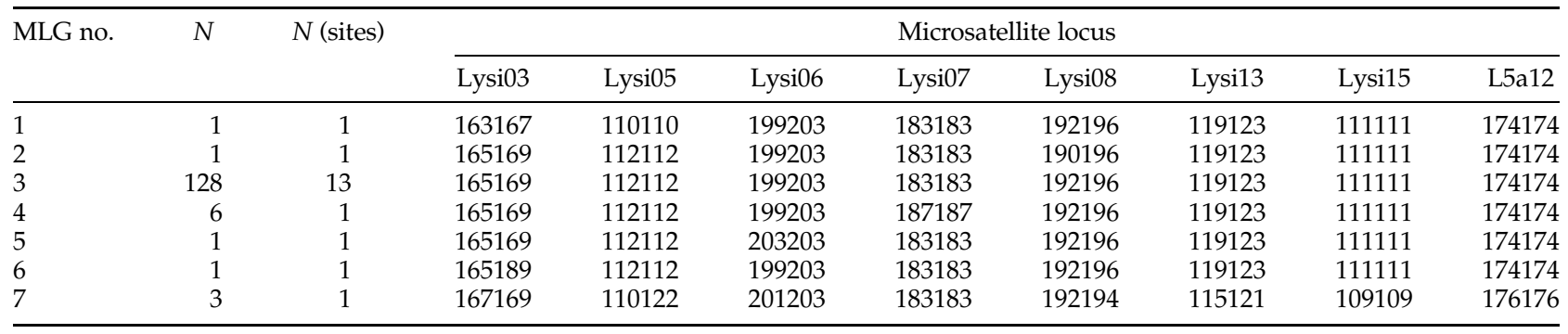

former reports of asexual reproduction in L. cardui and sexual reproduction in L. fabarum on C. vulgare (Starý, 2006).

\section{Genetic relationships among populations}

The UPGMA tree of all Lysiphlebus samples showed complete separation between $L$. fabarum and $L$. cardui (fig. 1b). Most L. cardui samples from A. f. cirsiiacanthoides clustered closely together because they essentially consisted of the same asexual lineage. Only the population 'Buchs $\mathrm{ZH}^{\prime}$ (no. 5 in fig. 1) was clearly differentiated from all other L. cardui populations because it contained individuals belonging to the second, morphologically cryptic asexual lineage (MLG 7 in table 2). STRUCTURE identified the highest probability for $K=3$ populations, corresponding to L. fabarum and the two cryptic L. cardui lineages (fig. 1c).

\section{Discussion}

This study showed that parasitoid wasps of the L. fabarum group exploiting aphids living on C. vulgare belong to two genetically and morphologically distinct lineages with different reproductive modes. Those showed virtually perfect host specialization in the same microhabitat. Mummies of $A$. $f$. cirsiiacanthoides exclusively yielded female wasps morphologically belonging to L. cardui, whereas mummies of $B$. cardui yielded wasps of both sexes with $L$. fabarum morphology, even when the two aphid species formed mixed colonies on the very same plants. The entire primary parasitoid community using $A$. f. cirsiiacanthoides as a host was strongly dominated by a single asexual MLG with L. cardui morphology, but we also discovered a second, genetically distinct but morphologically cryptic asexual L. cardui lineage (table 2, fig. 1b, c).

Considering that host-associated genetic differentiation of various strengths is observed across the entire L. fabarum group (Sandrock et al., 2011a), some degree of host specialization was expected here, especially since Starý (2006) already reported phenotypic differences between wasps from $B$. cardui and $A$. f. cirsiiacanthoides. More surprising was the complete lack of overlap in host use, even when the two aphids formed mixed colonies. In general, there is evidence that hostassociated populations of L. fabarum group parasitoids are connected by gene flow (Sandrock et al., 2011a), suggesting less than perfect host specialization. This is further supported by the observation that wasps collected from different hosts can often be reared on the same host ( $A$. fabae) in the laboratory (e.g., Sandrock et al., 2010). Even sexual and asexual populations do not show complete reproductive isolation in the $L$. fabarum group, because asexual lineages are known to spontaneously (albeit very rarely) produce males that can cross-breed with females of sexual populations (Belshaw et al., 1999; Sandrock \& Vorburger, 2011). Yet in the present case with two syntopic hosts belonging to different aphid genera, specialization and reproductive isolation of their Lysiphlebus parasitoids appear to be very strong if not complete. This indicates selection for fitness-related traits associated with host use and against hybridization. The present system of Lysiphlebus on C. vulgare is unlikely to represent an example of syntopic divergence, because Lysiphlebus lineages found on other aphid-plant associations genetically fall between the lineages found on C. vulgare (Sandrock et al., 2011a), but it does show that host specialization and reproductive isolation are upheld when recently evolved parasitoid lineages using different host species meet in the same microhabitat. Still unclear is how the strict host specialization is maintained. Does it reflect perfect host choice by ovipositing females or are the two parasitoid lineages even unable to develop in the alternative host? The complete lack of overlap is certainly suggestive of the latter, but this remains to be tested. The role of reproductive mode variation for the evolution of host specialization is unclear because both, sexual and asexual, parasitoids showed the same high degree of host specificity.

Aphid parasitoids on C. vulgare are themselves hosts of generalist as well as host-associated hyperparasitoid wasp species. Especially P. aphidis appears to preferentially exploit the mummies of $B$. cardui containing the sexual L. fabarum primary parasitoids $\left(F_{1,14}=6.20, P=0.026\right.$, table 1$)$. That host associations cascade upwards to the hyperparasitoid level on the same plant has been reported before (reviewed in Sullivan, 1987), but here we found it surprising, given that the two Lysiphlebus host-lineages $(97.3 \%$ of all collected aphid parasitoids) are closely related and presumably not even differentiated at the species level (Sandrock et al., 2011a). Again, the question remains whether this result reflects a preference for the aphid species (mummies of B. cardui tend to be slightly larger), the aphid parasitoid inside the mummy, or a difference in survival between the two environments. The much lower relative proportion of hyperparasitoids in $A$. $f$. cirsiiacanthoides mummies compared to $B$. cardui mummies is interesting with respect to biological control. It would suggest that asexual parasitoids may be better suited for biological control not only because of their faster reproduction, but possibly also because of lower rates of hyperparasitism.

Finally, the strong genetic differentiation among sampling sites is indicative of very limited and local dispersal of L. fabarum, although the lack of isolation by distance at least at the geographic scale of our study does not support this interpretation. However, note that the patterns of genetic 
differentiation were estimated unreliably because of small sample sizes of sexual females per site, and that they may have been distorted from collecting closely related individuals within sites (see the Results section). Very limited dispersal was previously proposed for L. cardui (Weisser \& Völkl, 1997), as well as for Lysiphlebus hirticornis, a specialized parasitoid of the tansy aphid, Metopeurum fuscoviride (Nyabuga et al., 2011). Thus, aphid parasitoids of the genus Lysiphlebus may generally be poor dispersers. This is in contrast to the aphid hosts of Lysiphlebus, especially from the genus Aphis, which migrate over large distances and show a very limited spatial population structure. In samples of $A$. fabae covering large parts of Europe, only about $5 \%$ of the molecular variation was explained by differences among sites (Sandrock et al., 2011b). Different mobilities could be of importance for the study of aphid-parasitoid co-evolution, because local adaptation evolves more readily in the antagonist with the higher dispersal ability (Gandon et al., 1996). This would generate the testable prediction that aphids tend to be locally adapted to their Lysiphlebus parasitoids, rather than the other way around.

\section{Acknowledgements}

Special thanks go to Christoph Sandrock for his help in the laboratory, for answering many analytical questions and for sharing his impressive knowledge. Furthermore, we would like to thank Uli Reyer for his comments on the manuscript, Sandra Röthlisberger for help during laboratory work and David Nash for statistical advice. This study was funded by the Swiss National Science Foundation and the Institute of Environmental Studies at the University of Zurich.

\section{References}

Andrews, F.G. (1978) Taxonomy and Host Specificity of Nearctic Alloxystinae: With a Catalog of the World Species (Hymenoptera: Cynipidae). State of California, Department of food and agriculture, Division of plant industry, Laboratory services.

Arnaud-Haond, S. \& Belkhir, K. (2007) Genclone: a computer program to analyse genotypic data, test for clonality and describe spatial clonal organization. Molecular Ecology Notes 7, 15-17.

Belshaw, R., Quicke, D.L.J., Völk1, W. \& Godfray, H.C.J. (1999) Molecular markers indicate rare sex in a predominantly asexual parasitoid wasp. Evolution 53, 1189-1199.

Berlocher, S.H. \& Feder, J.L. (2002) Sympatric speciation in phytophagous insects: moving beyond controversy? Annual Review of Entomology 47, 773-815.

Blackman, R.L. \& Eastop, V.F. (2000) Aphids on the World's Crops: An Identification and Information Guide. 2nd edn. Chichester, John Wiley and Sons.

Bush, G.L. (1969) Sympatric host race formation and speciation in frugivorous flies of the genus Rhagoletis (Diptera, Tephritidae). Evolution 23, 237-251.

Cavalli-Sforza, L.L. \& Edwards, A.W.F. (1967) Phylogenetic analysis: models and estimation procedures. American Journal of Human Genetics 19 (3, Part I), 233-257.

Craig, T.P., Horner, J.D. \& Itami, J.K. (1997) Hybridization studies on the host races of Eurosta solidaginis: implications for sympatric speciation. Evolution 51, 1552-1560.

de Vere Graham, M.W.R. (1969) The Pteromalidae of North-western Europe (Hymenoptera: Chalcidoidea). Supplement 16, London, Bulletin of the British Museum (Natural History).
Drès, M. \& Mallet, J. (2002) Host races in plant-feeding insects and their importance in sympatric speciation. Philosophical Transactions of the Royal Society of London. Series B: Biological Sciences 357, 471-492.

Earl, D.A. \& vonHolt, B.M. (2012) STRUCTURE HARVESTER: a website and program for visualizing STRUCTURE output and implementing the Evanno method. Conservation Genetics Resources. 4, 359-361. Available online at taylor0.biology. ucla.edu/structureHarvester/.

Erdös, J. (1964) Chalcidoidea III. in Fauna Hung. 73. Budapest, Akademiaikiado Budapest.

Ersts, P.J. (2007) Geographic distance matrix generator (version 1.2.3). American Museum of Natural History, Center for Biodiversity and Conservation. Available online at http:// biodiversityinformatics.amnh.org/open_source/gdmg.

Evenhuis, H.H. \& Kiriak, I.G. (1985) Studies on Alloxystidae (Hymenoptera, Cynipoidea) 8. Cynips minuta and Xystus minutus Hartig. Entomologische Berichten 45, 16-18.

Excoffier, L., Laval, G. \& Schneider, S. (2005) Arlequin (version 3.0): an integrated software package for population genetics data analysis. Evolutionary Bioinformatics 1, 47-50.

Falush, D., Stephens, M. \& Pritchard, J.K. (2003) Inference of population structure using multilocus genotype data: linked loci and correlated allele frequencies. Genetics 164, 1567-1587.

Fauvergue, X., Tentelier, C., Genson, G., Audiot, P., Guillemaud, T. \& Streiff, R. (2005) Microsatellite DNA markers for Lysiphlebus testaceipes. Molecular Ecology Notes 5, 109-111.

Feder, J.L., Forbes, A.A. (2010) Sequential speciation and the diversity of parasitic insects. Ecological Entomology 35, 67-76.

Fergusson, N.D.M. (1980) A Revision of British Species of Dendrocerus Ratzeburg (Hymenoptera: Ceraphronoidea) with a Review of their Biology as Aphid Hyperparasites. London, Bulletin of the British Museum (Natural History).

Forbes, A.A., Powell, T.H.Q., Stelinski, L.L., Smith, J.J. \& Feder, J.L. (2009) Sequential sympatric speciation across trophic levels. Science 323, 776-779.

Funk, D.J. (1998) Isolating a role for natural selection in speciation: host adaptation and sexual isolation in Neochlamisus bebbianae leaf beetles. Evolution 52, 1744-1759.

Gandon, S., Capowiez, Y., Dubois, Y., Michalakis, Y. \& Olivieri, I. (1996) Local adaptation and gene-for-gene coevolution in a metapopulation model. Proceedings of the Royal Society of London Series B-Biological Sciences 263, 1003-1009.

Gaston, K.J. (1991) The magnitude of global insect species richness. Conservation Biology 5, 283-296.

Godfray, H.C.J. (1994) Parasitoids: Behavioral and Evolutionary Ecology. Princeton, Princeton University Press.

Goudet, J. (2005) HIERFSTAT, a package for R to compute and test hierarchical F-statistics. Molecular Ecology Notes 5, 184-186. Available online at http://www2.unil.ch/popgen/softwares/ fstat.htm.

Guo, S.W. \& Thompson, E.A. (1992) Performing the exact test of Hardy-Weinberg proportion for multiple alleles. Biometrics 48, 361-372.

Jaenike, J. (1990) Host Specialization in phytophagous insects. Annual Review of Ecology and Systematics 21, 243-273.

Kavallieratos, N.G., Tomanović, Ž., Starý, P. \& Bogdanović, A.M. (2008) Parasitoids (Hymenoptera: Braconidae: Aphidiinae) attacking aphids feeding on Prunoideae and Maloideae crops in southeast Europe: aphidiinae-aphid-plant associations and keys. Zootaxa 1793, $47-64$. 
Klinkhamer, P.G.L. \& de Jong, T.J. (1993) Cirsium Vulgare (Savi) Ten. Journal of Ecology 81, 177-191.

Labandeira, C. \& Sepkoski, J. (1993) Insect diversity in the fossil record. Science 261, 310-315.

Langella, O. (1999) Populations 1.2.30. Available online at http:// bioinformatics.org/ tryphon/populations/.

Liepert, C. (1996) Chemische Mimikry bei Blattlausparasitoiden der Gattung Lysiphlebus (Hymenoptera, Aphidiidae). PhD Thesis, Universität Bayreuth, Germany.

Mayhew, P.J. (2007) Why are there so many insect species? Perspectives from fossils and phylogenies. Biological Reviews 82, 425-454.

Mitter, C., Farrell, B. \& Wiegmann, B. (1988) The phylogenetic study of adaptive zones: has phytophagy promoted insect diversification? American Naturalist 132, 107-128.

Müller, C.B., Adriaanse, I.C.T., Belshaw, R. \& Godfray, H.C.J. (1999) The structure of an aphid-parasitoid community. Journal of Animal Ecology 68, 346-370.

Nosil, P. (2007) Divergent host plant adaptation and reproductive isolation between ecotypes of Timema cristinae walking sticks. American Naturalist 169, 151-162.

Nyabuga, F.N., Loxdale, H.D., Heckel, D.G. \& Weisser, W.W. (2011) Temporal genetic structuring of a specialist parasitoid, Lysiphlebus hirticornis Mackauer (Hymenoptera: Braconidae) attacking a specialist aphid on tansy. Biological Journal of the Linnean Society 102, 737-749.

Page, R.D.M. (1996) Tree View: an application to display phylogenetic trees on personal computers. Computer Applications in the Biosciences 12, 357-358. Available online at taxonomy. zoology.gla.ac.uk/rod/treeview.html.

Parks, J.C. \& Werth, C.R. (1993) A study of spatial features of clones in a population of bracken fern, Pteridium aquilinum (Dennstaedtiaceae). American Journal of Botany 80, 537-544.

Pashley, D.P. (1986) Host-associated genetic differentiation in fall armyworm (Lepidoptera: Noctuidae): a sibling species complex. Annals of the Entomological Society of America 79, 898-904.

Pritchard, J.K., Stephens, M. \& Donelly, P. (2000) Inference of population structure using multilocus genotype data. Genetics 155, 945-959.

Quicke, D.L.J. (1997) Parasitic Wasps. London, Chapman and Hall.

Raymond, M. \& Rousset, F. (1995) GENEPOP (Version 1.2): population genetics software for exact tests and ecumenicism. Journal of Heredity 86, 248-249. Available online at http://kimura.univ-montp2.fr/ rousset/Genepop.htm.

Rosenberg, N.A. (2004) Distruct: a program for the graphical display of population structure. Molecular Ecology Notes 4, 137-138. Available online at http://www.stanford.edu/ group/rosenberglab/distruct.html.

Rousset, F. (1997) Genetic differentiation and estimation of gene flow from F-statistics under isolation by distance. Genetics 145, 1219-1228.

Sandrock, C. \& Vorburger, C. (2011) Single-locus recessive inheritance of asexual reproduction in a parasitoid wasp. Current biology 21, 433-437.

Sandrock, C., Frauenfelder, N., von Burg, S. \& Vorburger, C. (2007) Microsatellite DNA markers for the aphid parasitoid
Lysiphlebus fabarum and their applicability to related species. Molecular Ecology Notes 7, 1080-1083.

Sandrock, C., Gouskov, A. \& Vorburger, C. (2010) Ample genetic variation but no evidence for genotype specificity in an all-parthenogenetic host-parasitoid interaction. Journal of Evolutionary Biology 23, 578-585.

Sandrock, C., Schirrmeister, B. \& Vorburger, C. (2011a) Evolution of reproductive mode variation and host associations in a sexual-asexual complex of aphid parasitoids. BMC Evolutionary Biology 11, 348.

Sandrock, C., Razmjou, J. \& Vorburger, C. (2011b) Climate effects on life cycle variation and population genetic architecture of the black bean aphid, Aphis fabae. Molecular Ecology 20, 4165-4181.

Schluter, D. (2001) Ecology and the origin of species. Trends in Ecology and Evolution 16, 372-380.

Slatkin, M. (1995) A measure of population subdivision based on microsatellite allele frequencies. Genetics 139, 457-462.

Smith, J.M. (1966) Sympatric speciation. American Naturalist 100, 637-650.

Sneath, P.H.A. \& Sokal, R.R. (1973) Numerical Taxonomy: The Principles and Practice of Numerical Classification. San Francisco, Freeman.

Starý, P. (1966) Aphid Parasitoids of Czechoslovakia: A Review of the Chechoslovak Aphidiidae, Hymenoptera. Prague, Czechoslovak Academy of Science.

Starý, P. (1999) Biology and distribution of microbe-associated thelytokous populations of aphid parasitoids (Hym., Braconidae, Aphidiinae). Journal of Applied Entomology 123, 231-236.

Starý, P. (2006) Aphid Parasitoids of the Czech Republic (Hymenoptera: Braconidae, Aphidiinae). Prague, Academia.

Stireman, J.O. III, Nason, J.D. \& Heard, S.B. (2005) Hostassociated genetic differentiation in phytophagous insects: general phenomenon or isolated exceptions? Evidence from a goldenrod-insect community. Evolution 59, 2573-2587.

Stireman, J.O. III, Nason, J.D., Heard, S.B. \& Seehawer, J.M. (2006) Cascading host-associated genetic differentiation in parasitoids of phytophagous insects. Proceedings of the Royal Society B: Biological Sciences 273, 523-530.

Stork, N.E. (1988) Insect diversity: facts, fiction and speculation. Biological Journal of the Linnean Society 35, 321-337.

Sullivan, D.J. (1987) Insect hyperparasitism. Annual Review of Entomology 32, 49-70.

Tomanović, Ž., Kavallieratos, N.G., Starý, P., Stanisavljević, L. Ž., Ćetković, A., Stamenković, S., Jovanović, S. \& Athanassiou, C.G. (2009) Regional tritrophic relationship patterns of five aphid parasitoid species (Hymenoptera: Braconidae: Aphidiinae) in agroecosystem-dominated landscapes of southeastern Europe. Journal of Economic Entomology 102, 836-854.

Weir, B.S. \& Cockerham, C.C. (1984) Estimating F-statistics for the analysis of population structure. Evolution 38, 1358-1370.

Weisser, W.W. \& Völkl, W. (1997) Dispersal in the aphid parasitoid, Lysiphlebus cardui (Marshall) (Hym, aphidiidae). Journal of Applied Entomology-Zeitschrift für Angewandte Entomologie 121, 23-28. 